Article

\title{
c-Jun N-Terminal Kinase as a Therapeutic Target in Experimental Autoimmune Encephalomyelitis
}

\author{
Maud Bagnoud ${ }^{1,2,3, *, \dagger}$, Myriam Briner ${ }^{1,2, \dagger}$, Jana Remlinger 1,2,3 Ivo Meli $^{1,2}$, Sara Schuetz ${ }^{1,2}$,

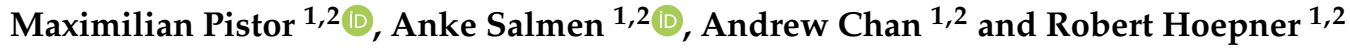 \\ 1 Department of Neurology, Inselspital, Bern University Hospital, University of Bern, 3010 Bern, Switzerland; \\ myriam.briner@insel.ch (M.B.); jana.remlinger@insel.ch (J.R.); ivo.meli@extern.insel.ch (I.M.); \\ sara.schuetz@bioinformatics.unibe.ch (S.S.); maximilian.pistor@insel.ch (M.P.); anke.salmen@insel.ch (A.S.); \\ andrew.chan@insel.ch (A.C.); robert.hoepner@insel.ch (R.H.) \\ 2 Department of Biomedical Research, University of Bern, 3010 Bern, Switzerland \\ 3 Graduate School for Cellular and Biomedical Sciences, University of Bern, 3010 Bern, Switzerland \\ * Correspondence: maud.bagnoud@insel.ch; Tel.: +41-31-6323076 \\ + These authors contributed equally to this work.
}

Received: 3 September 2020; Accepted: 16 September 2020; Published: 23 September 2020

\begin{abstract}
Jun N-terminal kinase (JNK) is upregulated during multiple sclerosis relapses and at the peak of experimental autoimmune encephalomyelitis (EAE). We aim to investigate the effects of pharmacological pan-JNK inhibition on the course of myelin oligodendrocyte glycoprotein ( $\left.\mathrm{MOG}_{35-55}\right)$ EAE disease using in vivo and in vitro experimental models. EAE was induced in female C57BL/6JRj wild type mice using MOG $35-55$. SP600125 (SP), a reversible adenosine triphosphate competitive pan-JNK inhibitor, was then given orally after disease onset. Positive correlation between SP plasma and brain concentration was observed. Nine, but not three, consecutive days of SP treatment led to a significant dose-dependent decrease of mean cumulative $\mathrm{MOG}_{35-55}$ EAE severity that was associated with increased mRNA expression of interferon gamma (INF- $\gamma$ ) and tumor necrosis factor alpha (TNF- $\alpha$ ) in the spinal cord. On a histological level, reduced spinal cord immune cell-infiltration predominantly of CD3+ T cells as well as increased activity of Iba1+ cells were observed in treated animals. In addition, in vitro incubation of murine and human CD3+ T cells with $\mathrm{SP}$ resulted in reduced $\mathrm{T}$ cell apoptosis and proliferation. In conclusion, our study demonstrates that pharmacological pan-JNK inhibition might be a treatment strategy for autoimmune central nervous system demyelination.
\end{abstract}

Keywords: multiple sclerosis; immunotherapy; mitogen-activated protein kinases; MAPK; SP600125; neuroinflammation

\section{Introduction}

Multiple sclerosis (MS) is an inflammatory and degenerative disorder of the central nervous system (CNS) [1]. Mitogen-activated protein kinases (MAPKs) have been shown to be involved in the regulation of cytokine gene expression, immune cell differentiation, neuronal-cell-death pathways and regulation of astrocyte inflammatory genes [2,3]. Consequently, they might influence both pathomechanisms of MS; neuroinflammation and degeneration. More precisely, MAPKs are divided into three subfamilies: The c-Jun N-terminal kinases (JNKs), the extracellular signal-regulated kinases (ERKs) and the p38 mitogen-activated protein kinases (p38) [4]. Originally, JNKs were named stress-activated protein kinases (SAPKs) due to their ability to respond to different environmental stressors such as ultraviolet irradiation, osmotic shock or oxidative stress [5]. Later, it was demonstrated that cytokines, hormones or morphogenic factors were also able to activate the c-Jun N-terminal kinase (JNK) pathway [6]. 
In mammals, three Jnk genes have been described. Of these, Jnk1 and Jnk2 are ubiquitously expressed, whereas $J n k 3$ is exclusively found in heart, brain and testis [7].

The JNK pathway has been proposed to be an important player in several neurological and autoimmune disorders [8,9], and particular in MS where upregulation of JNK activity has been observed in peripheral blood mononuclear cells (PBMCs) of relapsing MS patients compared to healthy volunteers [10]. Moreover, an increase of phosphorylated JNK (p-JNK) was found in the spinal cords of myelin basic protein (MBP) experimental autoimmune encephalomyelitis (EAE) Lewis rats during the acute phase of the disease [11]. Non-specific as well as specific inhibition of the JNK pathway has also demonstrated some beneficial effects in the myelin oligodendrocyte glycoprotein (MOG $\left.{ }_{35-55}\right)$ EAE. For instance, $\mathrm{N}$-acetylcysteine amide (AD4), a copper chelator, attenuates $\mathrm{MOG}_{35-55}$ disease severity by scavenging reactive oxygen species, by reducing matrix metallopeptidases activation and by inhibiting p38 and JNK phosphorylation [12]. It has also been shown that Paeoniflorin, which is extracted from the roots of Paeonia lactiflora, ameliorates $\mathrm{MOG}_{35-55}$ EAE disease severity by decreasing Th17 cell differentiation and by inhibiting dendritic cell function via the suppression of the IKK/NFkB and JNK pathway [13]. In addition, preventive treatment with SP600125 (SP), a JNK inhibitor, reduces the $\mathrm{MOG}_{35-55}$ EAE disease severity in wild type (WT) mice [14]. However, the genetic knockout of Jnk2 did not lead to differences in $\mathrm{MOG}_{35-55}$. EAE disease course compared to wild type C57BL/6JRj (C57BL/6) mice [15], whereas knockout of Jnk1 moderately ameliorated EAE disease course [16].

A mouse model with a pan-JNK knockout as well as studies investigating the treatment effect of a pharmacological pan-JNK inhibition in a therapeutic setting are lacking.

Therefore, our goal was to investigate, whether pharmacological inhibition of all JNK isoforms in a therapeutic setting may have the potential to ameliorate $\mathrm{MOG}_{35-55}$ EAE disease course. Given positive findings in vivo, we further aimed at subsequently translating the results to the human situation by performing in vitro studies in murine and human CD3+ T cells in parallel.

\section{Materials and Methods}

Animal and human studies were approved by the local authorities (Office of Agriculture and Nature Bern, Switzerland: 101/16; Cantonal Ethic Committee Bern, Switzerland: 2017-00060). C57BL/6JRj (C57BL/6) WT mice were ordered from Janvier Labs (Le-Genest-Saint-Isle, France) and housed under conventional housing conditions at the in-house animal facility of the University of Bern.

\subsection{In Vivo and In Vitro Treatments}

JNK inhibition was performed using SP600125 (SP), a pan-JNK inhibitor (Seleck Chemicals, Houston, TX, USA). SP was chosen for our experiments as it is a non-toxic reversible adenosine triphosphate (ATP) competitive inhibitor of JNK with similar specificity especially for the immunological relevant JNK isoforms 1 and 2 [17]. SP concentration used for the in vitro experiments was set to $10 \mu \mathrm{M}$ and for in vivo experiments to 15 and $30 \mathrm{mg} / \mathrm{kg} /$ day.

\subsection{Active Myelin Oligodendrocyte Glycoprotein $\left(M O_{35-55}\right)$ Experimental Autoimmune Encephalomyelitis $\left(M_{35}-55\right.$ EAE)}

Active $\mathrm{MOG}_{35-55}$ EAE was induced in 8 weeks old female C57BL/6 WT mice following our previously described $\mathrm{MOG}_{35-55}$ EAE induction protocol [18]. Briefly, animals were immunized by subcutaneous injection of $100 \mu \mathrm{g} \mathrm{MOG}_{35-55}$ peptide (Institute of Medical Immunology, Charité, Berlin, Germany) in phosphate-buffered saline solution (PBS; Thermo Fisher Scientific, Dreieich, Germany) emulsified in complete Freund's adjuvant containing $100 \mu \mathrm{g}$ mycobacterium tuberculosis (Difco, Detroit, MI, USA), followed by $200 \mathrm{ng}$ pertussis toxin (Quadratech, Epsom, UK; intraperitoneal (i.p.) injection, days 0 and 2). Animals were scored daily in a blinded manner using a 10-point EAE scale [18]. In addition to EAE scoring, body weight, which is a well-established parameter of drug side effects [19], was measured daily and a clinical assessment of side effects based on body weight and observation of the animals' behavior was performed. Treatment was initiated when animals had an EAE score 
22. SP ( 15 or $30 \mathrm{mg} / \mathrm{kg} /$ day (Sigma-Aldrich, MO, USA), solvent: Dimethyl sulfoxide (DMSO, final DMSO (Sigma-Aldrich) concentration 10\% in peanut oil (Migros, Zurich, Switzerland)) oral gavage; and control (10\% DMSO in peanut oil, oral gavage) were given on three or nine consecutive days.

\subsection{Apoptosis Assay}

CD3+ T cells were isolated from the spleen of C57BL/6 WT mice or from human PBMCs sampled from healthy donors by negative magnetic-activated cell sorting (MACS) selection (Pan-T cell isolation kit $\AA$, Miltenyi Biotec, NRW, Germany). CD3+ T cells were resuspended at $1 \mathrm{mio} / \mathrm{ml}$ in T cell medium (RPMI 1640 medium, Life Technologies, CA, USA) containing 10\% fetal bovine serum (FBS, Life Technologies), 1\% penicillin/streptomycin (P/S, Thermo Fisher Scientific) and 1\% L-glutamine (Life Technologies)). Cells were plated in a round bottom 96-well plate at a concentration of 100000 cells/well. Murine CD3+ T cells were stimulated with concanavalin A (conA, $1.5 \mu \mathrm{g} / \mathrm{mL}$, Sigma-Aldrich) and human CD3+ T cells with phytohemagglutinin (PHA, $2.5 \mu \mathrm{g} / \mathrm{mL}$, Sigma-Aldrich). Both murine and human CD3+ T cells were treated with SP $(10 \mu \mathrm{M}$, dissolved in DMSO, final DMSO concentration in the experiment $0.1 \%$ ). Apoptosis (Annexin V/Propidium iodide, Becton Dickinson Bioscience, NJ, USA) was analyzed by flow cytometry after $24 \mathrm{~h}$ for murine and $72 \mathrm{~h}$ for human CD3+ T cells, respectively.

\subsection{Proliferation Assay}

Murine and human CD3+ T cells were isolated and cultivated as described in the subsection apoptosis assay. Murine cells were collected after $48 \mathrm{~h}$ and human cells after $72 \mathrm{~h}$ and proliferation was assessed by flow cytometry using carboxyfluorescein succinimidyl ester staining (CFSE, Thermo Fisher Scientific).

\subsection{RNA Isolation}

Splenic-derived CD3+ T cells, spinal cords and brains were isolated from control (CD3+ T cells and spinal cords: $n=5$; brains: $n=9$ ) or SP-treated (CD3+ T cells and spinal cords: $n=5$; brains: $n=9$; $30 \mathrm{mg} / \mathrm{kg} /$ day) mice at peak of $\mathrm{MOG}_{35-55}$ EAE disease corresponding to day 4 after treatment initiation (for disease course and body weight of the mice see Figures A1 and A2). RNA was extracted following manufacturer's instructions (RNeasy Kit, Qiagen, Hilden, Germany). Complementary DNA (cDNA) was prepared from $1 \mu \mathrm{g}$ RNA mixed with Quanta qScript cDNA SuperMix (VWR International, Radnor, PA, USA). Reverse transcription was done using a thermal program of $5 \min 25^{\circ} \mathrm{C}, 30 \min 42{ }^{\circ} \mathrm{C}$ and 5 $\min 85^{\circ} \mathrm{C}$. RNA was stored at $-80^{\circ} \mathrm{C}$.

\subsection{Quantitative Real-Time Reverse Transcription Polymerase Chain Reaction ( $q R T-P C R)$ and Analysis}

Expression of interferon gamma (INF- $\gamma$ ), tumor necrosis factor alpha (TNF- $\alpha$ ), interleukin-4 (IL-4), interleukin-10 (IL-10) and interleukin-17 (IL-17) genes was analyzed using qRT-PCR with primers from Thermo Fisher Scientific (INF- $\gamma$ : Mm01168134_m1; TNF- $\alpha$ : Mm00443258_m1; IL-4: Mm445259_m1; IL-10: Mm01288386_m1; and IL-17: Mm00439618_m1). Transcripts were amplified using TaqMan qRT-PCR (TaqMan universal mastermix: KAPPA PROBE FAST Universal, Sigma-Aldrich, Louis, MO, USA). Experiments were run on an ABI7500 (Applied Biosystems, Foster City, CA, USA). Gene expression was normalized to housekeeping gene Rps18 coding for the Ribosomal Protein S18 (Mm02601777_g1, Thermo Fisher Scientific). The standard curve method of comparative quantification was used to analyze results [20].

\subsection{Protein Analysis}

Spinal cords and brains were isolated from $\operatorname{control}(n=9)$ or SP-treated $(n=9,30 \mathrm{mg} / \mathrm{kg} /$ day $)$ mice at peak of MOG $_{35-55}$ EAE disease corresponding to day 4 after treatment initiation (for disease course and body weight of the mice see Figure A2). Proteins were extracted following manufacturer's instructions (Tissue Extraction Reagent I, Invitrogen, CA, USA). INF- $\gamma$ and TNF- $\alpha$ protein concentrations were 
measured using commercially available ELISA kits (INF- $\gamma$ : ab100690, Abcam, Cambridge, UK; TNF- $\alpha$ : 88-7324, Invitrogen).

\subsection{Histology}

Spinal cords were isolated from control $(n=9)$ or SP-treated $(n=9,30 \mathrm{mg} / \mathrm{kg} /$ day $)$ mice at peak of $\mathrm{MOG}_{35-55}$ EAE disease corresponding to day 4 after treatment initiation (for disease course and body weight of the mice see Figure A2), dehydrated and embedded in paraffin. Then, $5 \mu \mathrm{m}$ thick tissue sections were stained with hematoxylin and eosin (H\&E) or luxol fast blue/periodic acid Schiff. CD3+ and Mac3 + cells were detected via immunohistochemistry, whereas GFAP+ and Iba1+ cells were visualized after immunofluorescence staining (CD3 (primary antibody): Rat- $\alpha$-human CD3, 1:100, AbD Serotec, Düsseldorf, Germany; Mac3 (primary antibody): Rat- $\alpha$-mouse Mac3, 1:100; BD Pharmingen, Heidelberg, Germany; CD3 and Mac3 (secondary antibody): Biotinylated rabbit- $\alpha$-rat IgG, 1:200, Vector Labs, CA, USA; GFAP (primary antibody): Chicken- $\alpha$-GFAP, 1:1000, Abcam; GFAP (secondary antibody): Goat- $\alpha$-chicken AF488, 1:1000, Thermo Fisher; and Iba1 (primary antibody): Rabbit- $\alpha$-Iba1, 1:200, Wako, Osaka, Japan; Iba1 (secondary antibody): Goat- $\alpha$-rabbit AF555, 1:1000, Thermo Fisher). Images were acquired with a slide scanner (Pannoramic 250 Flash III, 3DHISTECH, Budapest, Hungary). For each spinal cord segment (cervical, thoracic and lumbar), four different regions of interest (ROI) were examined except for demyelination where the complete white matter was analyzed. CD3+ and Mac3+ cell infiltrations were determined using CaseViewer (3DHISTECH). The percentage of white matter demyelination, GFAP and Iba1 fluorescence intensity as well as the roundness of Iba1+ cells were determined with ImageJ (National Institute of Mental Health, NIH, Bethesda, MD, USA).

\subsection{Mass Spectrometry}

The liquid chromatography-mass spectrometry (LC-MS) system with an autosampler was a Shimadzu LC-20A (Shimadzu, Japan) coupled with Applied Biosystem Sciex (MDS Sciex, Canada) API 5500 Tandem quadrapole mass spectrometer. The autosampler was SIL-HTC and the LC pump was LC-20AD, both from Shimadzu. The chromatographic integration was performed by Analyst software (version: 1.6.3; Applied Biosystems). Chromatographic separation was performed on a Phenomenex Kinetex C18 2.6u 2.1 by $50 \mathrm{~mm}$ analytical column and the mobile phase was $0.1 \%(v / v)$ formic acid in water and $0.1 \%(\mathrm{v} / \mathrm{v})$ formic acid in acetonitrile with a gradient, injection volume of $6 \mu \mathrm{L}$ and flow rate of $0.4 \mathrm{~mL} / \mathrm{min}$. Total analysis time of a single injection was 3 minutes and 30 seconds. Column oven temperature and autosampler temperature was set to $25^{\circ} \mathrm{C}$ and $6{ }^{\circ} \mathrm{C}$, respectively.

The LC eluent was introduced via electrospray ionization using a Turbo IonSpray interface set at $600{ }^{\circ} \mathrm{C}$ to generate positive ions $[\mathrm{M}+\mathrm{H}]+$. Ionization was assisted with nebulizer and IonSpray gas (nitrogen) at 7 (arbitrary units) and $10 \mathrm{~L} / \mathrm{min}$, respectively. The IonSpray potential was maintained at $5 \mathrm{kV}$. During $\mathrm{ms} / \mathrm{ms}$ analysis, the collision energies used ranged from 25 to $37 \mathrm{~V}$ and the scan speed was $10 \mathrm{Da} / \mathrm{sec}$. Quantification was performed by multiple reaction monitoring of the protonated precursor ion and the related product ion for both test article and internal standard (IS, propranolol) using the IS method with a peak area ratio and a linear least-squares regression curve with weighting factor of $1 / \times 2$. The mass transitions used for test article and propranolol were $m / z 221.0 \rightarrow 165.0$ and $\mathrm{m} / \mathrm{z}$ $260.2 \rightarrow 116.2$, respectively.

Stock solutions of test article and propranolol were prepared in DMSO and further diluted in ethanol. Calibration standards of eight concentration levels were prepared freshly and spiked into drug-free plasma or brain homogenate with test article stock solutions to give concentrations of 0.00116 , $0.00231,0.00463,0.0139,0.0417,0.125,0.500$ and $2.0 \mu \mathrm{M}$.

Brain samples (accurately weighed) were homogenized to a final dilution of $3 \times(w / v)$ in 50:50 methanol:water using ceramic beads. Vigorous shaking and rotation at high revolution (known as bead blasting) of the brain and diluent against the metal beads inside a capped sample tube disrupts the cellular structure and effects homogenization of individual samples with zero carryover in preparation, 
as the beads are only used once. Blank brain samples were treated in the same manner and used for the calibration curve matrix.

Plasma and brain homogenates were aliquoted and the test article was extracted via protein precipitation with 5 volumes of acetonitrile containing $20 \mathrm{nM}$ propranolol as the internal standard vortexed for 5 minutes, followed by centrifugation at $4000 \mathrm{rpm} / \mathrm{min}$ on a cooling centrifuge for 10 minutes at $25^{\circ} \mathrm{C}$. The supernatant was withdrawn and diluted 1:1 with LC-MS grade water before injection on the LC-MS system. The limit of quantification was of $1.16 \mathrm{nM}$.

\subsection{Statistical Analysis}

Data are expressed as mean $+/-$ standard error of the mean (SEM). Comparison of data was performed using Kruskal-Wallis Test (KWT) or Mann-Whitney test (MWT), depending on the number of group comparisons, for independent and Wilcoxon signed rank sum test (WSRST) for dependent measurements. Association between SP serum and brain tissue concentration was analyzed using Pearson correlation coefficient. Gene expression and protein data were calculated as X-fold change of SP compared to control-treated animals and plotted as mean and $95 \%$-confidence interval $(95 \%-\mathrm{CI})$. In this analysis-as 1-fold represents no significant difference-a one-sample t-test (OSTT) was used with the test value of 1 to investigate gene regulation by SP. To determine if EAE score or cumulative SP dose influence body weight, a multivariate linear regression analysis was run. In this regression models, body weight at end of disease was used as dependent variable and EAE score, dose group of $\mathrm{SP}$ and an interaction term between the latter as independent variables. Data of the regression analysis is given as coefficient (coef) and 95\%-CI. Significance was assumed for all tests if $p$-value was $<0.05$.

\section{Results}

\subsection{Plasma and Brain SP Concentrations of SP $30 \mathrm{mg} / \mathrm{kg} /$ day-Treated Acute $M_{O} \mathrm{G}_{35-55}$ EAE-Diseased Mice Positively Correlate}

Preliminary data using a small cohort demonstrated that SP was detectable in the plasma of $5 / 6$ and in the brain of 4/6 SP $30 \mathrm{mg} / \mathrm{kg} /$ day-treated acute MOG $_{35-55}$ EAE-diseased mice, whereas it was undetectable in all four control mice. In more details, the mean plasma SP concentration of SP $30 \mathrm{mg} / \mathrm{kg} /$ day-treated acute MOG $_{35-55}$ EAE-diseased mice was of $3.35 \mathrm{nM}$ (SEM $0.45, n=5$ ), whereas the mean SP brain concentration was of $8.62 \mathrm{nM}$ (SEM 2.46, $n=4)$. Furthermore, positive correlation between SP plasma and brain concentration was noticed (Pearson $\mathrm{r}$ correlation, coefficient $0.97,95 \% \mathrm{CI}$ : $0.19-1.0, p<0.05$, Figure 1).

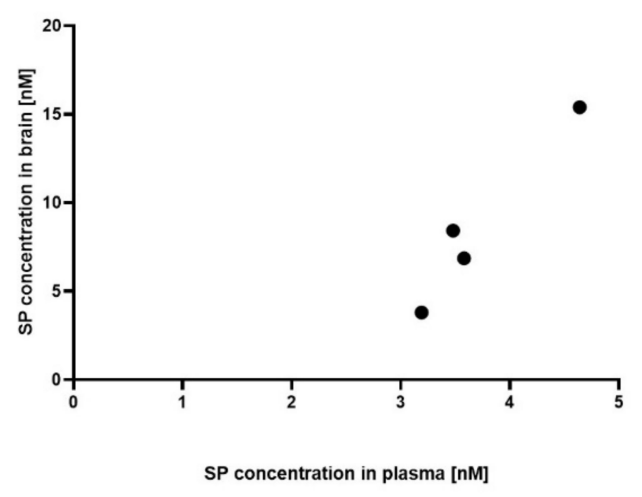

Figure 1. Association between plasma and brain SP600125 (SP) concentration. SP concentration was measured both in the plasma and in the brain of SP $30 \mathrm{mg} / \mathrm{kg} /$ day-treated acute myelin oligodendrocyte glycoprotein $\left(\mathrm{MOG}_{35-55}\right)$ experimental autoimmune encephalomyelitis (EAE)-diseased mice $(n=4)$. $n=2$ pairs had no detectable values in brain or plasma samples and were excluded. Mass spectrometry. Abbreviations: SP: SP600125. Statistic: Pearson r correlation, coefficient 0.97, 95\% CI: 0.19-1.0 and $p<0.05$. 


\subsection{Effects of Pharmacological Pan-JNK Inhibition on $M O G_{35-55}$ EAE Disease Course}

Two experimental setups were used to evaluate if pan-JNK inhibition is a potential strategy for treatment of acute demyelinating events: Drug administration over three consecutive days in analogy to treatment of MS relapses in the human setting versus drug administration over nine consecutive days imitating chronic treatment of autoimmune neuroinflammation. Short-term treatment over three consecutive days with either 15 or $30 \mathrm{mg} / \mathrm{kg} /$ day had no effect on the mean cumulative MOG $_{35-55}$ EAE score (KWT: Each $p>0.05$; Figure 2A) and on body weight (KWT: Each $p>0.05$; Figure 2B). In contrast, administration over nine consecutive days led to a reduction of mean cumulative $\mathrm{MOG}_{35-55}$ EAE score in the SP $15 \mathrm{mg} / \mathrm{kg} /$ day group by $24.0 \%$ (KWT: $p<0.0001$; Figure $2 \mathrm{C}$ ) and in the $30 \mathrm{mg} / \mathrm{kg} / \mathrm{day}$ group by $43.3 \%$ (KWT: $p<0.0001$; Figure 2C) compared to control treatment. This reduced clinical severity was accompanied by higher body weights of the 15 and $30 \mathrm{mg} / \mathrm{kg} /$ day SP-treated animals (mean percentage of body weight changes compared to control: SP $15 \mathrm{mg} / \mathrm{kg} /$ day $+0.9 \%$ (KWT: $p>0.05$ ) and SP $30 \mathrm{mg} / \mathrm{kg} /$ day $+4.3 \%$ (KWT: $p<0.0001$ ); Figure 2D).

In both experimental setups and treatment arms, no SP side effects on gross animal behavior were observed. Multivariate regression analysis demonstrated that weight loss was independent of treatment ( 3 days treatment: Coefficient $-0.1295 \%-C I-0.32-0.07, p=0.21 ; 9$ days treatment: Coefficient $0.0295-\% \mathrm{CI}-0.11-0.16 ; p=0.70$ ), but predicted by $\mathrm{MOG}_{35-55}$ EAE score in the control as well as the SP groups ( 3 days treatment: Coefficient $-4.795 \%-C I-5.2--4.2, p<0.001 ; 9$ days treatment: Coefficient $-8.195 \%-C I-9.1--7.1 ; p<0.001)$.

\subsection{JNK Inhibition Increases Spinal Cord INF- $\gamma$ and TNF- $\alpha$ mRNA Expression during the Acute Phase of $M O G_{35-55} E A E$}

In spinal cord, SP treatment ( $30 \mathrm{mg} / \mathrm{kg} /$ day) led to a 2.4-fold increased mRNA expression of IFN- $\gamma$ and a 2.1-fold increase of TNF- $\alpha$ mRNA expression compared to control mice in the acute phase of MOG $_{35-55}$ EAE (OSST (test value 1): $p<0.05$; Figure 3A), whereas IL-4, IL-10 and IL-17 were not differentially regulated (OSST (test value 1): Each $p$-value $>0.05$; Figure $3 \mathrm{~A}$ ). No significant different mRNA expression of INF- $\gamma$ and TNF- $\alpha$ was observed in the brains of SP-treated acute MOG $35-55$ EAE-diseased mice compared to control mice (OSST (test value 1): $p>0.05$, Figure A3). Spinal cord and brain protein expression of INF- $\gamma$ also did not significantly differ between the two groups (OSST (test value 1): $p>0.05$, Figure A4). In splenic-derived CD3+ T cells, no differential cytokine mRNA expression between SP (30 mg/ $/ \mathrm{kg} /$ day) and control treatment was detected (OSST (test value 1): Each $p$ $>0.05$; Figure 3B). Clinical disease course and body weight of the mice used for these experiments are shown in Figures A1 and A2. 

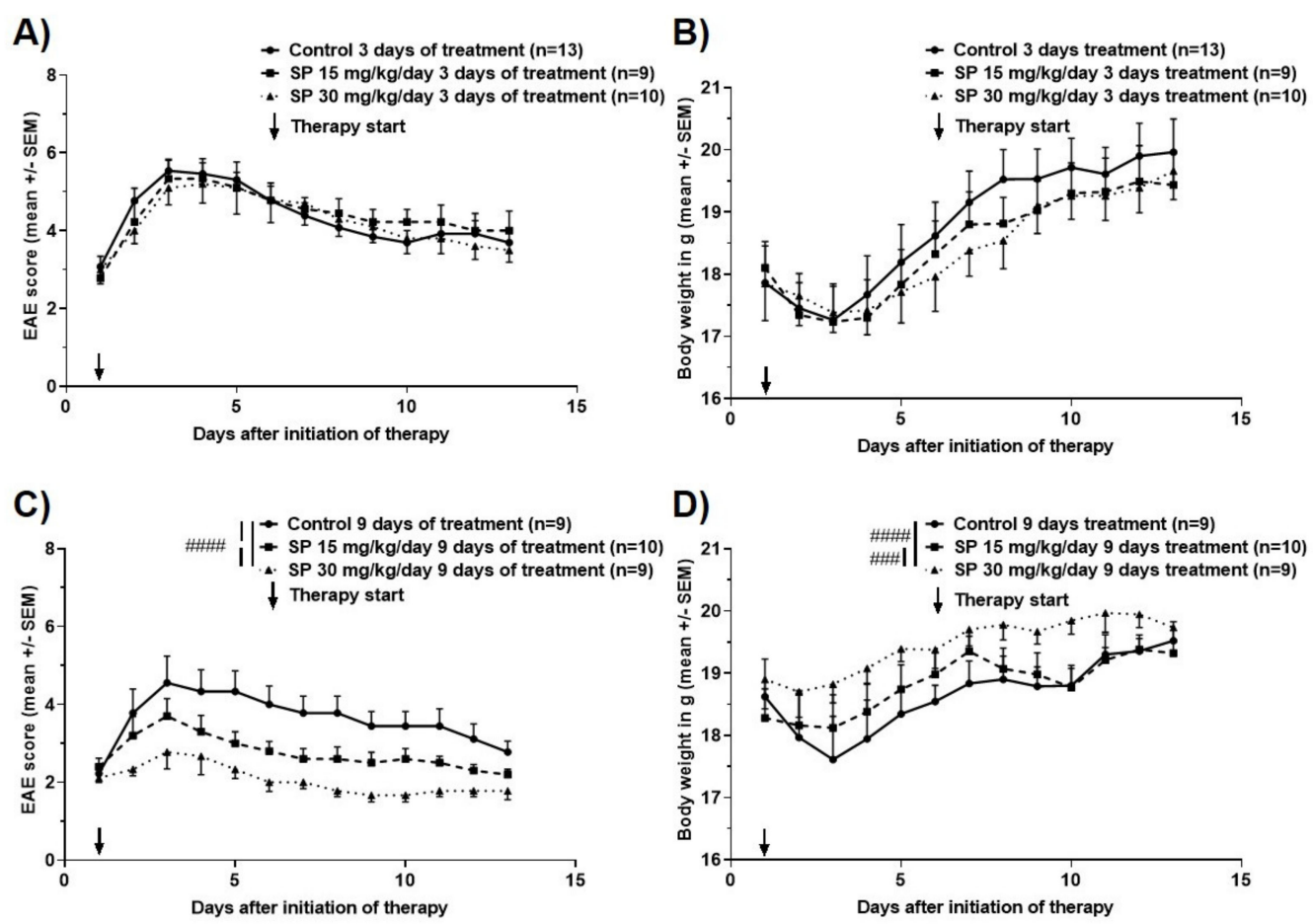

Figure 2. Clinical disease course of $\mathrm{MOG}_{35-55} \mathrm{EAE}$ in $\mathrm{C} 57 \mathrm{BL} / 6 \mathrm{JRj}$ wild type mice treated for (A) three or (C) nine consecutive days with control (dimethyl sulfoxide (DMSO (in peanut oil), SP600125 15 or $30 \mathrm{mg} / \mathrm{kg}$ /day. Body weight during course of $\mathrm{MOG}_{35-55}$ EAE in C57BL/6JRj wild type mice treated for (B) three or (D) nine consecutive days with control (DMSO in peanut oil), SP600125 15 or $30 \mathrm{mg} / \mathrm{kg} / \mathrm{day}$. Numbers of included animals are displayed in the graph. EAE score: 10 score system according to [18]. Abbreviations: EAE: Experimental autoimmune encephalomyelitis, SEM: Standard error of the mean and SP: SP600125. Statistic: Kruskal-Wallis Test: \#\#\# < 0.001 and \#\#\# < 0.0001.

A)

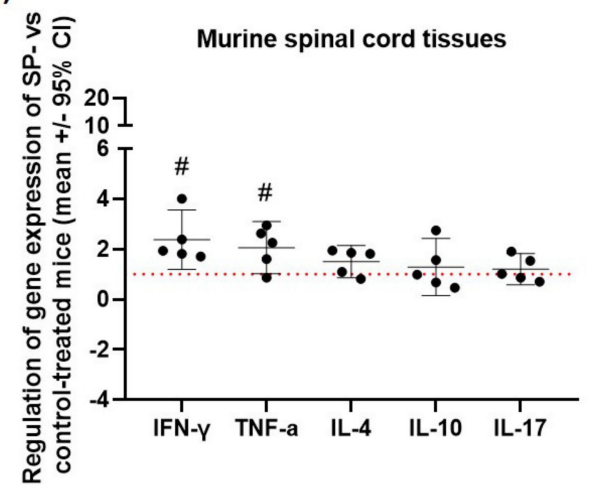

B)

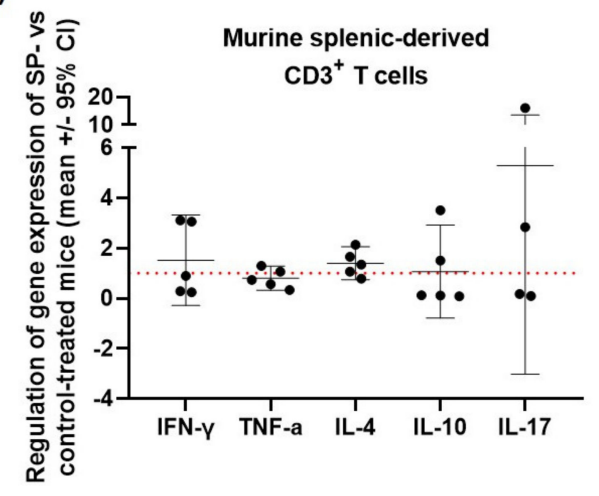

Figure 3. Effect of SP treatment on relative cytokine mRNA expression in (A) murine spinal cord of $\mathrm{MOG}_{35-55}$ EAE-diseased mice (acute phase) and in (B) murine splenic-derived CD3+ T cells of $\mathrm{MOG}_{35-55}$ EAE-diseased mice (acute phase). (A,B) X-fold difference in the relative expression of INF- $\gamma$, TNF- $\alpha$, IL-4, IL-10 and IL-17 (normalized to Rps18) in SP $30 \mathrm{mg} / \mathrm{kg} /$ day-treated mice compared to control mice. Control ( $n=5$, in triplicates), SP $30 \mathrm{mg} / \mathrm{kg} /$ day $(n=5$, in triplicates) and 3 days of treatment. qRT-PCR. Abbreviations: SP: SP600125, CI: Confidence of interval. Statistic: One-sample t-test \# $<0.05$. 


\subsection{JNK Inhibition Reduces Spinal Cord Cell-Infiltration during the Acute Phase of MOG ${ }_{35-55}$ EAE}

$\mathrm{SP} 30 \mathrm{mg} / \mathrm{kg} /$ day-treated acute $\mathrm{MOG}_{35-55}$ EAE-diseased mice showed a significant reduced spinal cord CD3+ T cell infiltration compared to control mice (MWT, $p<0.01$, Figure 4A). This reduced $\mathrm{CD} 3+\mathrm{T}$ cell infiltration is pronounced when looking at the cervical segment of the spinal cord (MWT, $p<0.0001$, Figure A5A). A trend at a $90 \%$ level of significance of a reduced Mac3+ cell infiltration in the overall spinal cord was also observed (MWT, $p=0.07$, Figure $4 \mathrm{~B}$ ) which was driven by the cervical segment (MWT, $p<0.0001$, Figure A5B). Significant increase of Iba1 fluorescence intensity, as well as a significant increase in the roundness of the Iba1+ cells was noticed in the lumbar segment of the spinal cord (MWT, $p<0.05$, Figure A6A-B) but no significance was observed when looking at the overall spinal cord (MWT, $p>0.05$, Figure $4 \mathrm{C}-\mathrm{D}$ ). No significantly different GFAP fluorescence intensity was observed between the two groups, neither in all nor in a specific segment (MWT, $p>0.05$, Figures $4 \mathrm{E}$ and $\mathrm{A} 6 \mathrm{C})$. Furthermore, no significant difference in white matter demyelination was noticed between the two groups (MWT, $p>0.05$, Figures $4 \mathrm{~F}$ and A5C).

A)

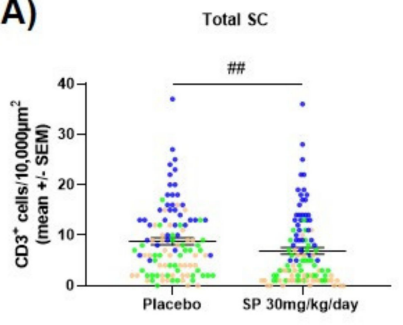

D)

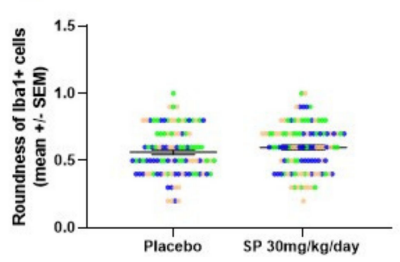

B)

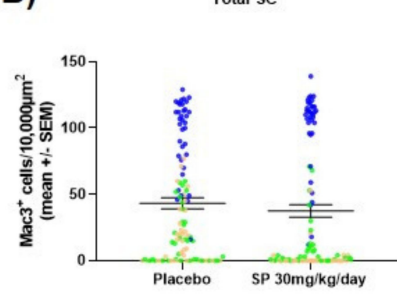

E)

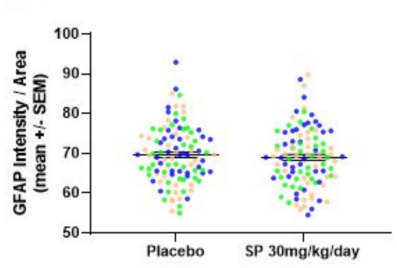

C)
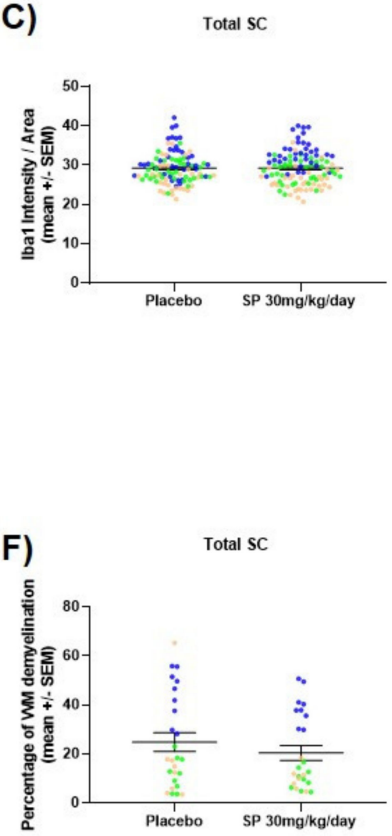

Figure 4. Effect of SP treatment on murine spinal cord (A) CD3+ cell infiltration, (B) Mac3+ cell infiltration, (C) Iba1 fluorescence intensity, (D) Iba1+ cell roundness, (E) GFAP fluorescence intensity and (F) white matter demyelination. Spinal cords were extracted from control or SP $30 \mathrm{mg} / \mathrm{kg} /$ day-treated MOG $_{35-55}$ EAE-diseased mice (acute phase). Three segments of each spinal cord (cervical, thoracic and lumbar) were evaluated and pooled. For each segment, four different regions of interest were analyzed except for demyelination where the complete white matter was analyzed. Control (n $=9), \mathrm{SP} 30 \mathrm{mg} / \mathrm{kg} /$ day $(n=9)$ and 3 days of treatment. (A-B) immunohistochemistry, (C-E) immunofluorescence and (F) luxol fast blue staining. Each dot represents a measurement. Orange dots show measurements of the cervical segment, green of the thoracic segment and blue of the lumbar segment of the spinal cord. Abbreviations: SC: Spinal cord, SEM: Standard error of the mean, SP: SP600125 and WM: White matter. Statistic: Mann-Whitney test, \#\# < 0.01 .

\subsection{JNK Inhibition Exerts Anti-Apoptotic and Anti-Proliferative Effects in Murine and Human CD3+T Cells}

SP administration reduced apoptosis and proliferation of CD3+ T cells from C57BL/6 WT mice and human healthy donors in vitro: Incubation of murine CD3+ T cells with SP $10 \mu \mathrm{M}$ resulted in a reduction of apoptosis by $5 \%$ compared to control (WSRST: $p<0.05$; Figure $5 \mathrm{~A}$ ) and reduced proliferation by $15 \%$ (WSRST: $p<0.01$; Figure 5B). Results in the human situation were more pronounced with a reduction 
of CD3+ T cell apoptosis by21\% (WSRST: $p<0.001$; Figure 5C) and decreased proliferation by $91 \%$ (WSRST: $p<0.001$; Figure 5D).

A)

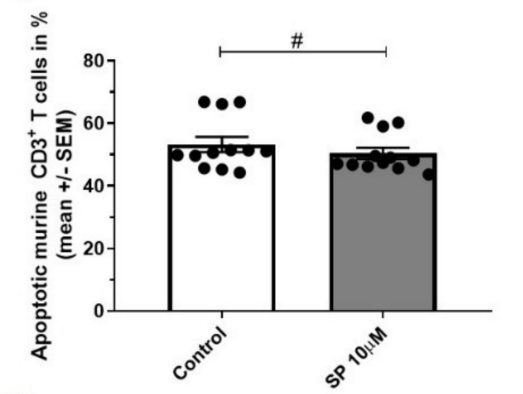

C)

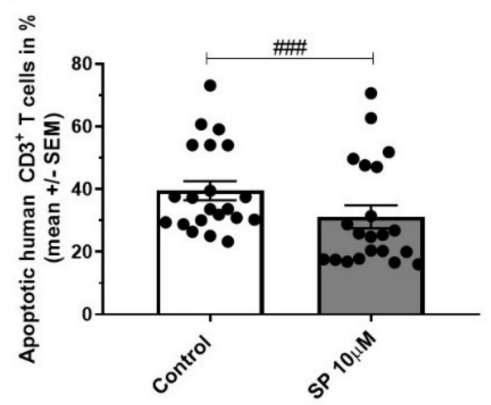

B)

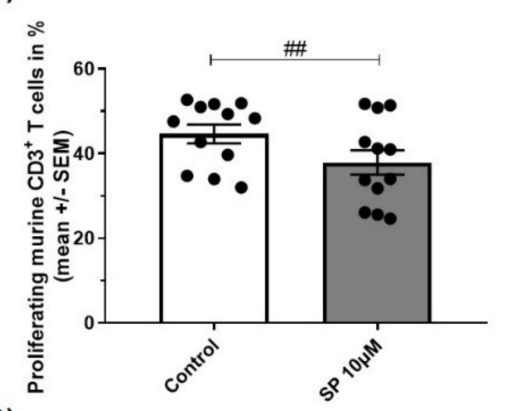

D)

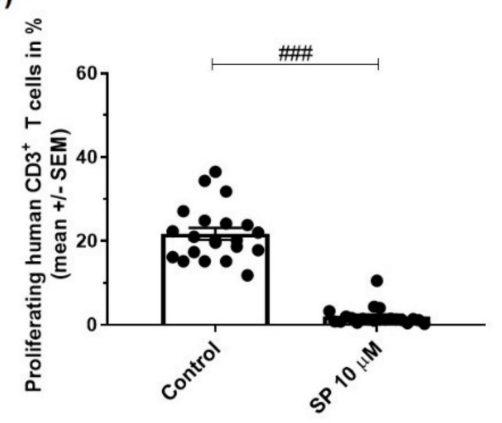

Figure 5. (A,C) apoptosis of CD3+ T cells of C57BL/6JRj mice (A, $n=4$ experiments in triplicates, stimulus concanavalin A (conA) $1.5 \mu \mathrm{g} / \mathrm{mL}, 24 \mathrm{~h}$ ) and healthy human controls (C, $n=7$ experiments in triplicates, stimulus phytohemagglutinin (PHA) $0.5 \mu \mathrm{g} / \mathrm{mL}, 72 \mathrm{~h}$ ). Incubation with control or SP $10 \mu \mathrm{M}$ (Annexin V/PI, flow cytometry). (B,D) proliferation of CD3+ T cells of C57BL/6JRj mice (B, $n$ $=4$ experiments in triplicates, stimulus conA $1.5 \mu \mathrm{g} / \mathrm{mL}, 24 \mathrm{~h})$ and healthy human controls $(\mathbf{D}, n=$ 7 experiments in triplicates, stimulus PHA $0.5 \mu \mathrm{g} / \mathrm{mL}, 72 \mathrm{~h}$ ). Incubation with control or SP $10 \mu \mathrm{M}$ (CFSE, flow cytometry). Abbreviations: SEM: Standard error of the mean and SP: SP600125. Statistic: Wilcoxon signed rank test \# $<0.05$, \#\# $<0.01$ and \#\#\# $<0.001$.

\section{Discussion}

Using two different in vivo treatment regimens, our study demonstrated that pharmacological pan-JNK inhibition ameliorates MOG $_{35-55}$ EAE disease course when administered after disease onset over nine consecutive days in a therapeutic setting. Effects of pan-JNK inhibition appear to be mediated by inhibition of $\mathrm{CD} 3+\mathrm{T}$ cell proliferation and apoptosis in the peripheral immune compartment and by regulation of cytokine expression and cell infiltration in the CNS (Figure 6). 


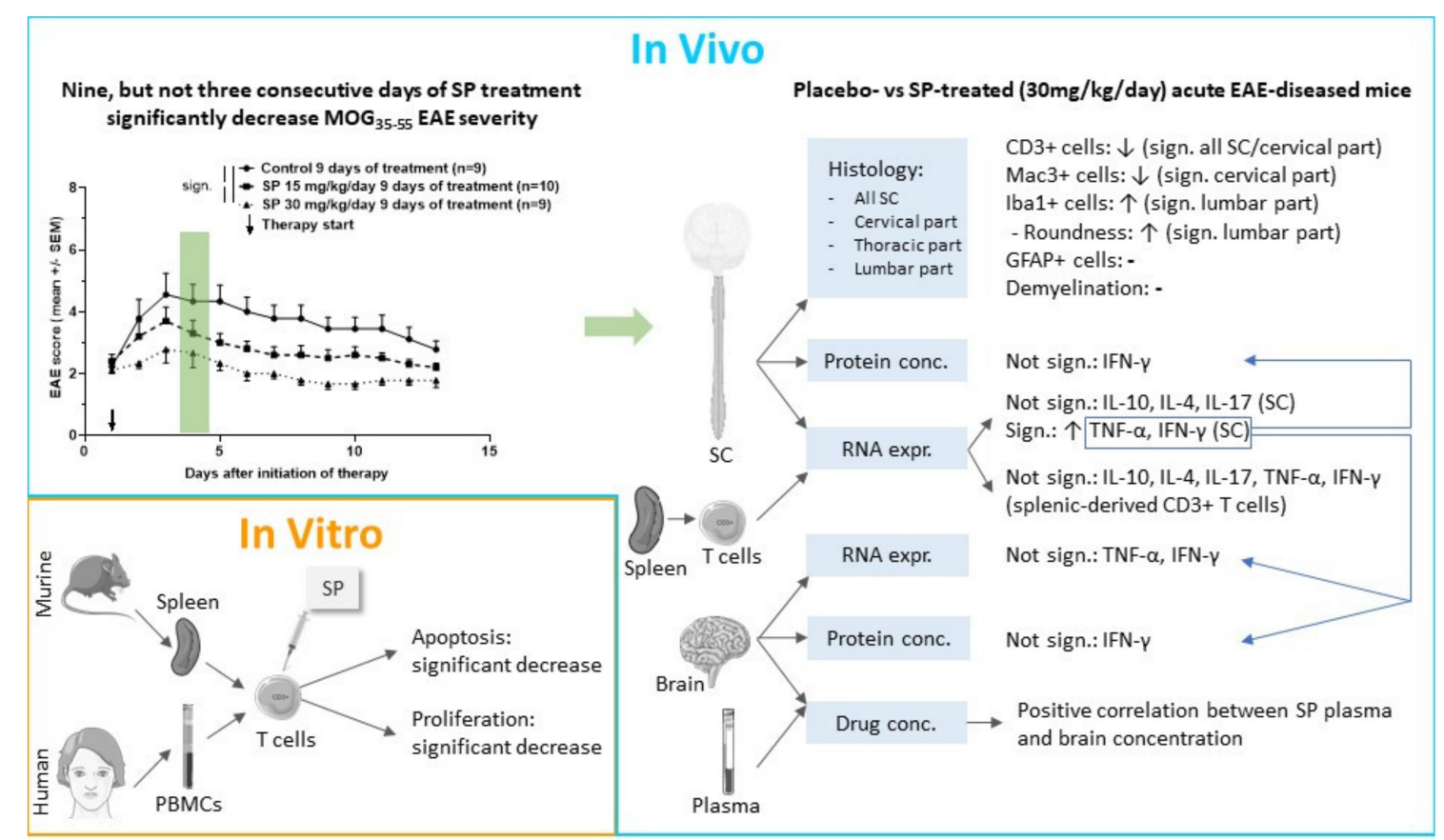

Figure 6. Graphical abstract summarizing key experiments and results of this study. Abbreviations: conc.: Concentration, EAE: Experimental autoimmune encephalomyelitis, expr.: Expression, sign.: Significant, SC: Spinal cord, SP: SP600125 and PBMCs: Peripheral blood mononuclear cells. This figure was created using Servier Medical Art templates licensed under a Creative Commons License (https://creativecommons.org/licenses/by/3.0/).

Clinical effects were detected in $\mathrm{MOG}_{35-55}$ EAE experiments using SP, a pharmacological pan-JNK inhibitor, given over nine consecutive days after disease onset. These findings contradict results of studies with JNK isoform-specific knockout models, which failed to demonstrate a significant impact on MOG $_{35-55}$ EAE disease course [6]. Considering that JNK1 and JNK2 have important, but overlapping functions [6], clinical effects of pharmacological pan-JNK inhibition with similar specificity for these two isoforms [17] may explain these results, because reduced activity of one isoform cannot be compensated by increased activity of the other. Taking into account that a Jnk-1/Jnk-2 double knockout has a lethal phenotype [21], drug safety of our pharmacological approach has to be addressed carefully. In this regard, our treatment regimen during either three or nine days of SP administration demonstrated no clinical signs of SP side effects like a pronounced reduction of body weight, altered animal behavior or even death. Regarding body weight as one parameter of drug toxicity [19], multivariate linear regression analysis demonstrated that no $\mathrm{MOG}_{35-55}$ EAE score-independent negative effect of SP treatment on body weight was present. Nevertheless, in addition to longer drug administration and higher dosages, other parameters of drug toxicity like drug serum and tissue concentration, hematological, liver and kidney parameters and daily food consumption should be investigated in the future to accurately study the feasibility of a pharmacological pan-JNK inhibition in the light of drug safety issues.

Plasma and brain tissue concentrations of SP were measured $24 \mathrm{~h}$ after the third oral gavage. Preliminary results demonstrated a strong positive correlation (Pearson coefficient 0.97) between plasma and brain SP concentration, indicating that SP crosses the blood-brain barrier. Concentrations in the brain were approximately 2.6-fold higher than in the plasma, which might point to a favorable CNS biodistribution of SP supporting the treatment efficacy in CNS disease.

Mechanistically, our study investigated cytokine regulation by SP during peak of MOG $35-55$ EAE disease in the peripheral immune (splenic-derived CD3+ T cells) and CNS compartment (spinal cord and brain). mRNA expression of Th1-derived cytokines (INF- $\gamma$, TNF- $\alpha$ ), Th2-derived cytokines (IL-4), 
Th17-derived cytokines (IL-17) and regulatory cytokines (IL-10) were analyzed both in splenic-derived CD3+ T cells and in the spinal cord of acute MOG $35-55$ EAE-diseased mice [22]. We observed an increased mRNA expression of INF- $\gamma$ and TNF- $\alpha$ in the spinal cord of SP $30 \mathrm{mg} / \mathrm{kg} /$ day-treated acute MOG $_{35-55}$ EAE-diseased mice compared to control, whereas peripheral cytokine mRNA expression measured in splenic-derived CD3+ T cells was not significantly regulated by SP. TNF- $\alpha$ and INF- $\gamma$ are both known to be secreted by different peripheral cells including T cells [23,24]. However, CNS-resident cells have also been shown to produce these two types of cytokines $[25,26]$ suggesting that these cell types could be responsible for the observed increased mRNA expression of TNF- $\alpha$ and INF- $\gamma$ in the spinal cord. In contrast, spinal cord protein expression of INF- $\gamma$ did not significantly differ between treatment groups. However, this result does not contradict the previous one knowing that mRNA and protein concentration do not necessarily correlate [27]. Moreover brain mRNA and protein expression of INF- $\gamma$ as well as brain mRNA of TNF- $\alpha$ were not affected by SP treatment, which is not surprising knowing that the EAE driven inflammation mainly affects the spinal cord [28]. TNF- $\alpha$ protein expression was also analyzed both in the spinal cord and brain of mice, however obtained values were below the detection range of the ELISA kit $(8 \mathrm{pg} / \mathrm{ml})$ prohibiting further analysis. Increased expression of INF- $\gamma$ and reduced EAE disease severity has to be discussed in detail, as INF- $\gamma$ was first described to exacerbate EAE and MS [29]. However, there is increasing evidence that INF- $\gamma$ has beneficial effects on EAE, e.g., mice deficient for INF- $\gamma$ or INF- $\gamma$ receptor or mice treated with a neutralizing INF- $\gamma$ monoclonal antibody have a more severe EAE disease course [30]. These contradictory findings of INF- $\gamma$ can be explained using a dynamic model of INF- $\gamma$ function under consideration of different EAE disease phases. More precisely, it has been proposed that INF- $\gamma$ promotes pathogenesis during the initiation phase, whereas it suppresses the disease during the acute phase [31,32]. Translated to our work, the finding of increased INF- $\gamma$ expression in spinal cord during the acute phase of MOG $_{35-55}$ EAE might represent one molecular mechanism, which finally leads to a less severe disease course in SP-treated mice. In addition to INF- $\gamma$ expression, TNF- $\alpha$ mRNA expression was upregulated in the spinal cord during the acute phase in SP $30 \mathrm{mg} / \mathrm{kg} /$ day-treated MOG $35-55$ EAE-diseased mice. The role of TNF- $\alpha$ in both EAE and MS is a matter of a controversial discussion. On one side, TNF inhibition has beneficial effects in EAE [33] and TNF receptor I deficiency leads to delayed EAE onset [34]. On the other side, results of a clinical trial using TNF inhibitor in MS patients were negative as MS disease was even worse in the treatment arm [35]. It has been demonstrated that mice lacking TNF show severe neurological impairment with extensive demyelination [36], and mice lacking the TNF receptor II have an increased disease severity [37]. Another study demonstrated the importance of differentiating the soluble and the membrane form of TNF with a detrimental role of soluble TNF and a beneficial role of the transmembrane TNF in EAE. In detail, they showed that soluble TNF enhances the production of pro-inflammatory mediators, whereas transmembrane TNF diminishes their production in CNS tissues at the peak of EAE disease [38]. In our study, the observed clinical effect of SP is associated with an increased TNF- $\alpha$ expression in the spinal cord during the acute phase of EAE disease, suggesting that increased TNF- $\alpha$ expression is associated with beneficial effects of SP treatment. However, a limitation of our study is that we are not able to differentiate between membrane-bound and soluble form of TNF by only analyzing the gene expression [25].

Several hallmarks such as T cell and macrophage CNS infiltration, demyelination or astrocyte and microglia activation characterize the EAE [39]. We observed a significant reduction of CD3+ T cell infiltration in the whole spinal cord during the peak of the disease. In more details, stronger significant reduction of $\mathrm{CD} 3+\mathrm{T}$ cell infiltration was observed when looking at the cervical part of the spinal cord. Despite it being still a matter of debate, various evidence points towards a role of JNK on T cell activation/function [40-44]. We showed in vitro that JNK inhibition influences murine CD3+ T cell proliferation and apoptosis, supporting our histological findings. There is sparse and inconclusive evidence for effects of JNK inhibition on proliferation. Indeed, some demonstrated that SP reduces T cell proliferation [17], whereas others observed no effect [45]. Regarding apoptosis, an influence of the JNK pathway on pro- and anti-apoptotic mechanisms depending on cell type and stimulus 
is described [44]. Hypothetical, the functional effects of SP can be explained by the fact that T cell apoptosis is reduced when anergy, expressed as lowest proliferation response, is maximal [46]. Anergic T cells were shown to be defective in JNK signaling [47] and hindered JUN activation due to inhibited autophagy [48]. Murine in vitro experiments were translated to the human situation, confirming that in vitro effects of a pan-JNK inhibition were comparable between murine and human CD3+ T cells. This gives experimental evidence that a pan-JNK inhibition might also be a potential treatment strategy in human MS disease.

Reduced CD3 $+\mathrm{T}$ cell infiltration was accompanied by a decreased macrophage, defined as Mac3+ cell, infiltration of the cervical part of the spinal cord. A beneficial effect of JNK inhibition on macrophage infiltration has already been reported in other diseases. Indeed, reduced macrophage infiltration into the colon has been observed in the dextran sulphate sodium (DSS)-induced colitis, an animal model of inflammatory bowel diseases, when treated with SP [49]. In addition, it has been demonstrated that activation of the JNK pathway was essential for the development and the survival of macrophages [50]. Moreover, the effect of JNK inhibition on both GFAP and Iba1 fluorescence intensity was analyzed. GFAP is commonly used to determine activated astrocytes [51,52], whereas Iba1 is a marker for both macrophages and microglia [53]. Iba1 fluorescence intensity as well as morphological analysis have been used to determine macrophage/microglia reactivity [54]. In our study, a significant increase of Iba1 fluorescence intensity, as well as a significant increase in the roundness of the Iba1+ cell was noticed in the lumbar segment of the spinal cord, which hints at an increased activity of microglia. Our findings are in line with previous data demonstrating that JNK inhibition with SP changes inflammatory metabolic activity of microglia after external pro-inflammatory stimulus with lipopolysaccharide in mice [55].

Despite effects on immune cell populations, we did not observe a statistically significant difference in white matter demyelination between control and SP $30 \mathrm{mg} / \mathrm{kg} /$ day-treated acute MOG $_{35-55}$ EAE-diseased mice. Nevertheless, the white matter demyelination was lower in SP-treated mice at peak of disease (mean control mice: 24.8\% (SEM 3.78); mean SP-treated mice: 20.5\% (SEM 3.07)), also reflecting reduced clinical $\mathrm{MOG}_{35-55}$ EAE severity in the SP treated animals. Indeed, c-Jun, a downstream target of JNK, has previously been shown to negatively regulate myelination by inhibiting different myelin genes and by favoring an immature state of the myelinating cells [56].

In our study, the effect of a pan-JNK inhibitor was analyzed and consequently no distinction between the different isoforms was made. However, it is worthwhile to mention that several studies point toward an important role of JNK3 inhibition in neuroprotection. Indeed, it has been observed that mice with a neural-specific Jnk3 deletion are more resistant to glutamate excitotoxicity [57], which has been shown to be deleterious in the EAE $[58,59]$. Furthermore, it has been shown that disruption of the $J n k 3$ gene render mice less sensitive to brain injury after cerebral ischemia and that it prevents the release of the cytochrome $c$ from the mitochondria after oxygen-glucose deprivation [60]. Interestingly, it has also been shown that both TNF- and TNF-related apoptosis-inducing ligand (TRAIL)-induced death of mature adult human oligodendrocytes are mediated by JNK3 [61,62]. Consequently, further investigations are warranted in order to define the therapeutic value of JNK inhibitors in MS better.

Findings of our experimental study should promote further investigations in the future taking into account clinical effects, biological mechanisms of action as well as drug tolerability of pan-JNK inhibition.

Author Contributions: M.B. (Maud Bagnoud) involved in conceptualization, data curation, formal analysis, investigation, methodology, project administration and writing (original draft). M.B. (Myriam Briner) involved in conceptualization, data curation, formal analysis, funding acquisition, investigation, methodology and writing (original draft). J.R. involved in formal analysis, methodology and writing (review and editing). I.M. involved in methodology and writing (review and editing). S.S. involved in investigation, methodology and writing (review and editing). M.P. involved in investigation and writing (review and editing). A.S. involved in project administration and writing (review and editing). A.C. involved in funding acquisition, investigation, resources and writing (review and editing). R.H. involved in conceptualization, formal analysis, funding acquisition, investigation, methodology, resources, supervision and writing (original draft). All authors have read and agreed to the published version of the manuscript. 
Funding: This research was funded by the Swiss National Fund (SNF no.310030_172952). Parts of the work were also supported by Burgergemeinde Bern.

Acknowledgments: We thank Celgene, Bristol Meyers Squibb Company, for the mass spectrometry experiments and here especially Annie Caudle and Samantha Richardson Bristol Myers Squibb, NCR\&D-DMPK 10300 Campus Point Drive San Diego California 92040. We also thank Steve Kirk for language editing.

Conflicts of Interest: MaB has nothing to declare. MyB received travel grants form Merck, Biogen and Sanofi Genzyme. JR, IM, MP and SS have nothing to declare. AS received speaker honoraria and/or travel compensation for activities with Almirall Hermal GmbH, Biogen, Merck, Novartis, Roche and Sanofi Genzyme, none related to this work. AC has received personal compensation for activities with Bayer, Biogen, Genzyme, Merck, Novartis, Roche, Teva. He received research support from the Swiss National Fonds (SNF, No. 310030_172952), Genzyme and UCB. RH received research and travel grants from Novartis and Biogen Idec. He also received speaker's honoraria from Biogen, Novartis, Merk and Almirall.

\section{Appendix A}
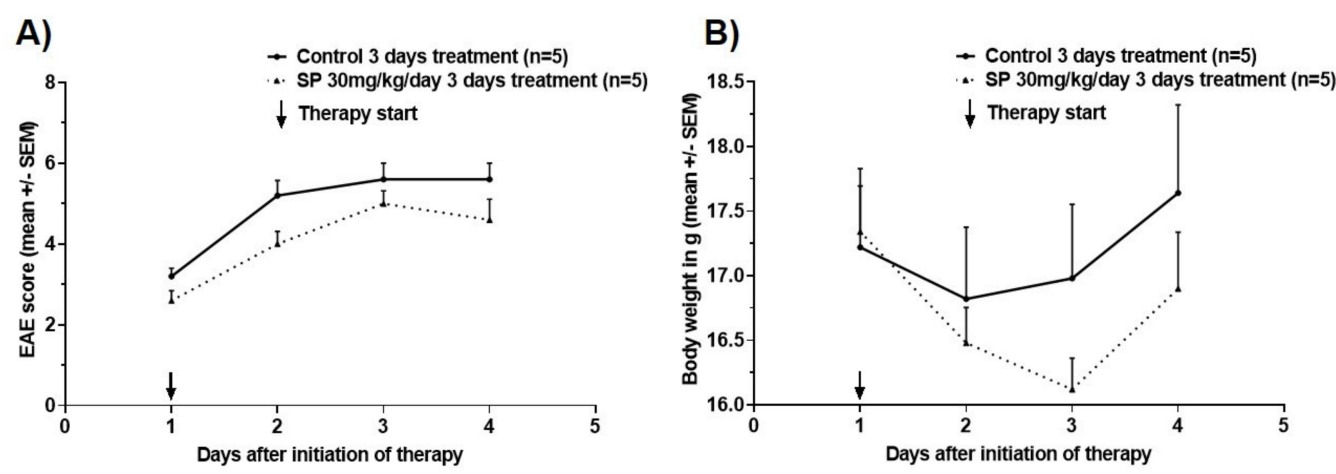

Figure A1. (A) clinical disease course of $\mathrm{MOG}_{35-55} \mathrm{EAE}$ in C57BL/6JRj wild type mice treated for three consecutive days with control (DMSO in peanut oil) or SP60012530 mg/kg/day. (B) body weight during course of $\mathrm{MOG}_{35-55}$ EAE in C57BL/6JRj wild type mice treated for three consecutive days with control (DMSO in peanut oil) or SP600125 $30 \mathrm{mg} / \mathrm{kg} /$ day. Numbers of included animals are displayed in the graph. EAE score: 10 score system according to [18]. Abbreviations: EAE: Experimental autoimmune encephalomyelitis, SEM: Standard error of the mean and SP: SP600125. Statistic: Mann-Whitney Test: n.s.

A)

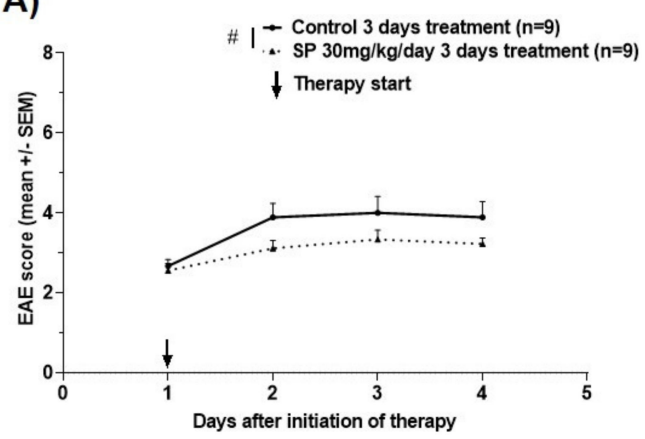

B)

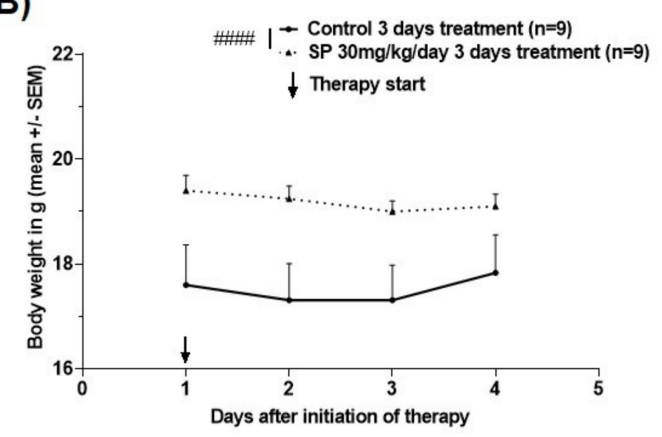

Figure A2. (A) clinical disease course of $\mathrm{MOG}_{35-55} \mathrm{EAE}$ in $\mathrm{C} 57 \mathrm{BL} / 6 \mathrm{JRj}$ wild type mice treated for three consecutive days with control (DMSO in peanut oil) or SP600125 $30 \mathrm{mg} / \mathrm{kg} / \mathrm{day}$. (B) body weight during course of $\mathrm{MOG}_{35-55}$ EAE in C57BL/6JRj wild type mice treated for three consecutive days with control (DMSO in peanut oil) or SP600125 $30 \mathrm{mg} / \mathrm{kg} /$ day. Number of included animals are displayed in the graph. EAE score: 10 score system according to [16]. Abbreviations: EAE: Experimental autoimmune encephalomyelitis, SEM: Standard error of the mean and SP: SP600125. Statistic: Mann-Whitney Test: $\#<0.05$ and \#\#\# < 0.0001 . 


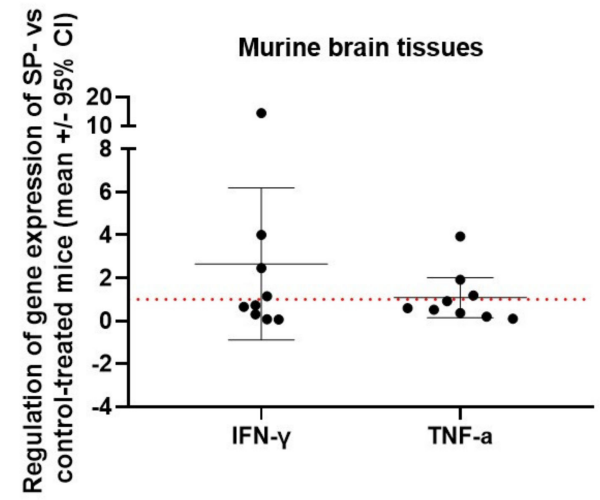

Figure A3. Effect of SP treatment on relative cytokine mRNA expression in murine brains of EAE-diseased mice (acute phase). X-fold difference in the relative expression of interferon gamma (INF- $\gamma$ ) and tumor necrosis factor alpha (TNF- $\alpha$ ) (normalized to Rps18) in SP $30 \mathrm{mg} / \mathrm{kg} /$ day-treated mice compared to control mice. Control ( $n=9$, in triplicates), SP $30 \mathrm{mg} / \mathrm{kg} / \mathrm{day}(n=9$, in triplicates) and 3 days of treatment. qRT-PCR. Abbreviations: SP: SP600125 and CI: confidence of interval. Statistic: one-sample $t$-test: n.s.

A)

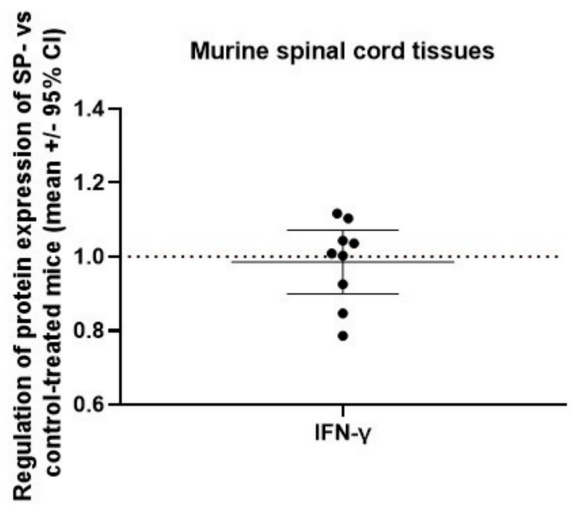

B)

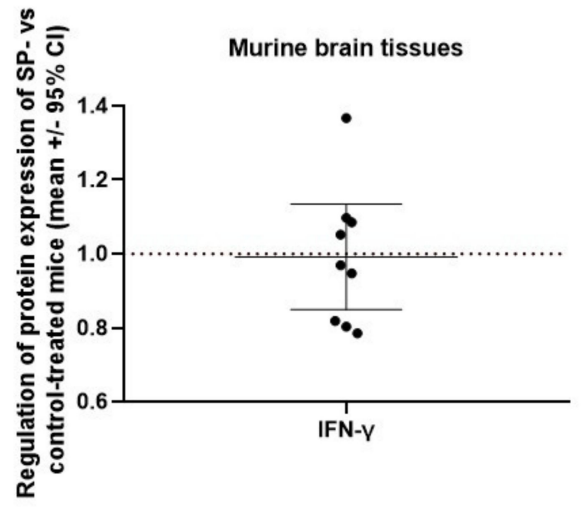

Figure A4. Effect of SP treatment on relative cytokine protein INF- $\gamma$ expression in (A) murine spinal cords and in (B) murine brains of EAE-diseased mice (acute phase). $\mathrm{X}$-fold difference in the relative expression of INF- $\gamma$ in SP $30 \mathrm{mg} / \mathrm{kg} /$ day-treated mice compared to control mice. Control $(n=9$, in triplicates), SP $30 \mathrm{mg} / \mathrm{kg} /$ day ( $n=9$, in triplicates) and 3 days of treatment. ELISA. Abbreviations: SP: SP600125 and CI: confidence of interval. Statistic: one-sample $t$-test: n.s. 
A)

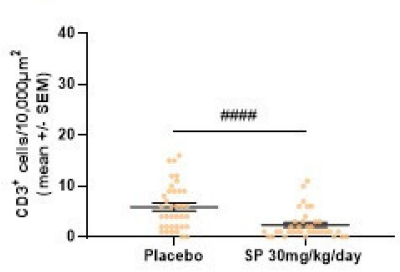

B)

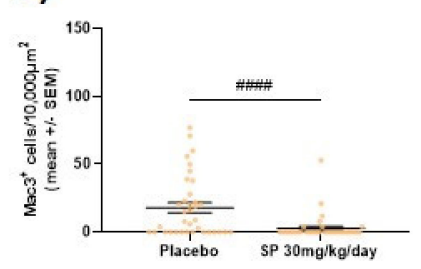

C)

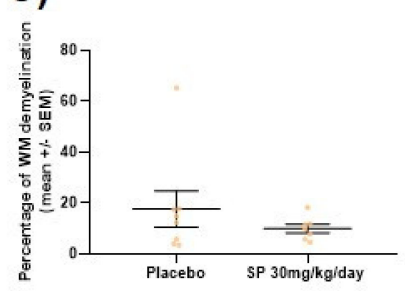

Thoracie region

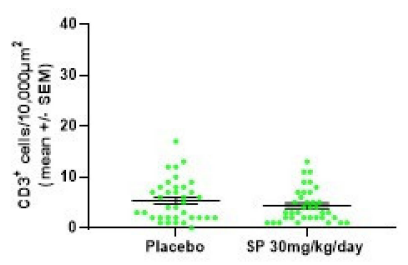

Thoracic region

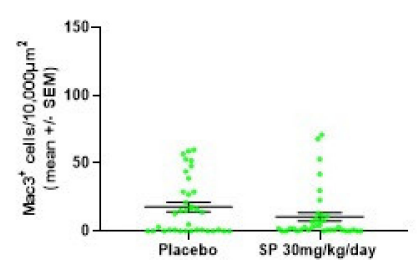

Thoracic region

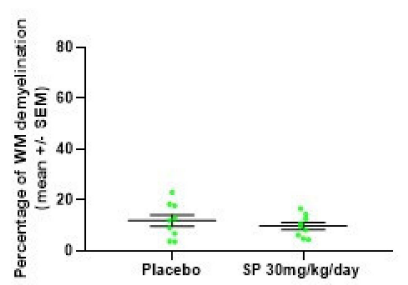

Lumbar region

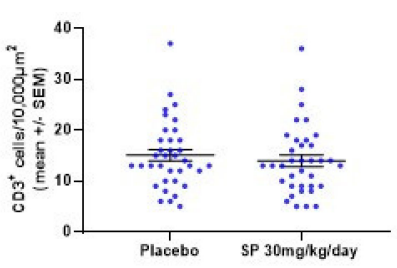

Lumbar region

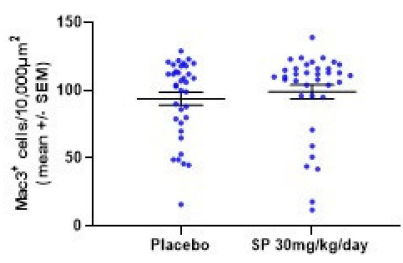

Lumbar region

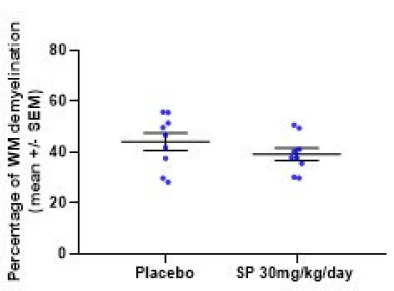

Figure A5. Effect of SP treatment on murine spinal cord (A) CD3+ cell infiltration, (B) Mac3+ cell infiltration and (C) demyelination. Spinal cords were extracted from control or SP $30 \mathrm{mg} / \mathrm{kg} /$ day-treated EAE-diseased mice (acute phase). Three segments of each spinal cord (cervical, thoracic and lumbar) were evaluated. For each segment, four different regions of interest were analyzed except for demyelination where the complete white matter was analyzed. Control $(n=9)$, SP $30 \mathrm{mg} / \mathrm{kg} / \mathrm{day}(n=9)$ and 3 days of treatment. (A-B) immunohistochemistry and (C) luxol fast blue staining. Each dot represents a measurement. Abbreviations: SC: spinal cord, SEM: standard error of the mean, SP: SP600125 and WM: White matter. Statistic: Mann-Whitney test, \#\#\# < 0.0001. 
A)

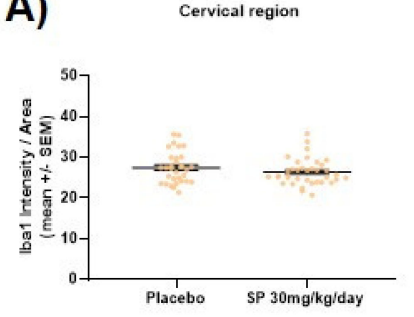

B)

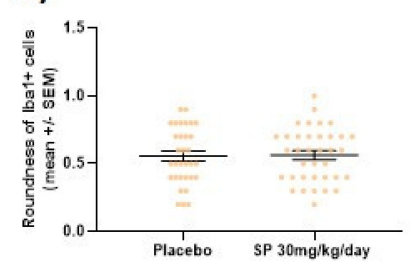

C)

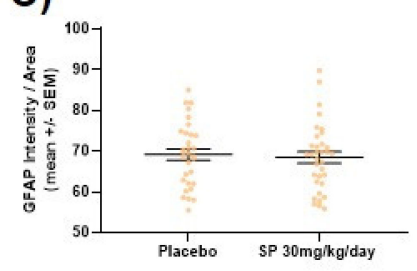

Thoracic region

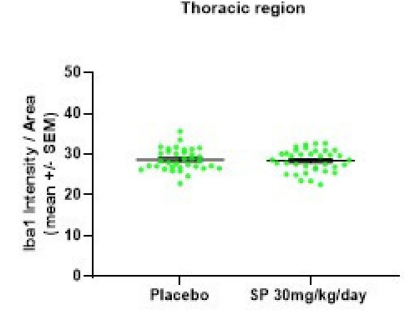

Thoracic region

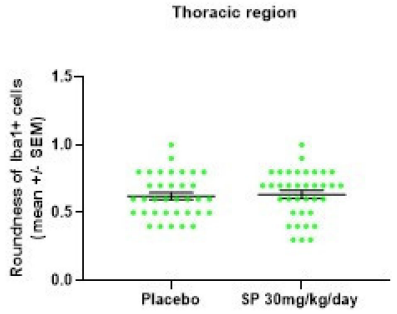

Thoracic region

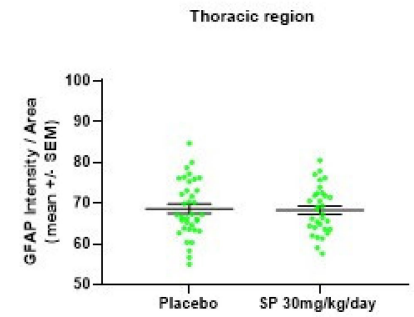

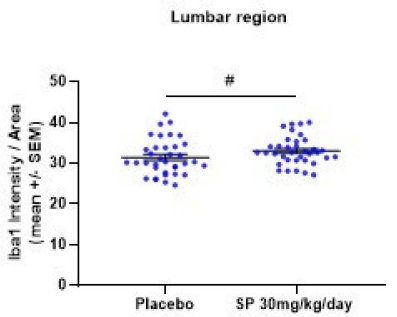
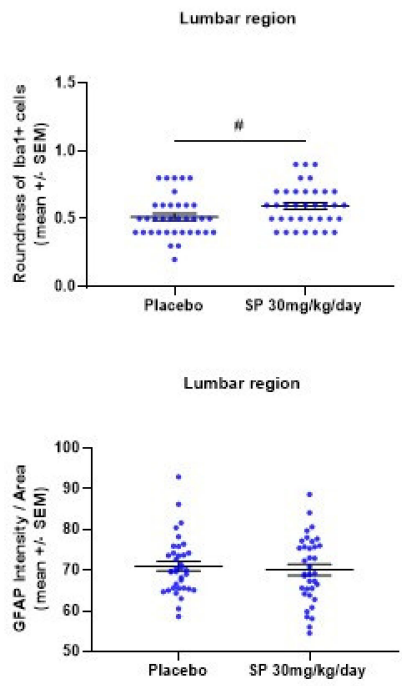

Figure A6. Effect of SP treatment on murine spinal cord (A) Iba1 fluorescence intensity, (B) Iba1+ cell roundness and (C) GFAP fluorescence intensity. Spinal cords were extracted from control or SP $30 \mathrm{mg} / \mathrm{kg} /$ day-treated EAE-diseased mice (acute phase). Three segments of each spinal cord (cervical, thoracic and lumbar) were evaluated. For each segment, four different regions of interest were analyzed. Control $(n=9)$, SP $30 \mathrm{mg} / \mathrm{kg} /$ day $(n=9)$ and 3 days of treatment. (A-C) immunohistochemistry. Each dot represents a measurement. Abbreviations: SC: Spinal cord, SEM: Standard error of the mean and SP: SP600125. Statistic: Mann-Whitney test, \#<0.05.

\section{References}

1. Goldenberg, M.M. Multiple sclerosis review. A Peer-Rev. J. Formul. Manag. 2012, 37, 175-184.

2. Davis, R.J. Signal transduction by the JNK group of MAP kinases. Cell 2000, 103, 239-252. [CrossRef]

3. Hua, L.L.; Zhao, M.L.; Cosenza, M.; Kim, M.O.; Huang, H.; Tanowitz, H.B.; Brosnan, C.F.; Lee, S.C. Role of mitogen-activated protein kinases in inducible nitric oxide synthase and TNFalpha expression in human fetal astrocytes. J. Neuroimmunol. 2002, 126, 180-189. [CrossRef]

4. Cobb, A.S.K.A.M.H. MAP Kinase Pathways: Functions and Modulation. Available online: https://pdfs. semanticscholar.org/e817/98ebf70c233741ada55e0666ea96927e5b4a.pdf (accessed on 21 September 2020).

5. Tibbles, L.A.; Woodgett, J.R. The stress-activated protein kinase pathways. Cell. Mol. Life Sci. 1999, 55, 1230-1254. [CrossRef] [PubMed]

6. Zeke, A.; Misheva, M.; Remenyi, A.; Bogoyevitch, M.A. JNK Signaling: Regulation and Functions Based on Complex Protein-Protein Partnerships. Microbiol. Mol. Biol. Rev. 2016, 80, 793-835. [CrossRef] [PubMed]

7. Johnson, G.L.; Nakamura, K. The c-jun kinase/stress-activated pathway: Regulation, function and role in human disease. Biochim. Biophys. Acta 2007, 1773, 1341-1348. [CrossRef]

8. Cui, J.; Zhang, M.; Zhang, Y.Q.; Xu, Z.H. JNK pathway: Diseases and therapeutic potential. Acta Pharmacol. Sin. 2007, 28, 601-608. [CrossRef]

9. Roy, P.K.; Rashid, F.; Bragg, J.; Ibdah, J.A. Role of the JNK signal transduction pathway in inflammatory bowel disease. World J. Gastroenterol. 2008, 14, 200-202. [CrossRef] 
10. Ferrandi, C.; Richard, F.; Tavano, P.; Hauben, E.; Barbie, V.; Gotteland, J.P.; Greco, B.; Fortunato, M.; Mariani, M.F.; Furlan, R.; et al. Characterization of immune cell subsets during the active phase of multiple sclerosis reveals disease and c-Jun N-terminal kinase pathway biomarkers. Mult. Scler. 2011, 17, 43-56. [CrossRef]

11. Shin, T.; Ahn, M.; Jung, K.; Heo, S.; Kim, D.; Jee, Y.; Lim, Y.K.; Yeo, E.J. Activation of mitogen-activated protein kinases in experimental autoimmune encephalomyelitis. J. Neuroimmunol. 2003, 140, 118-125. [CrossRef]

12. Offen, D.; Gilgun-Sherki, Y.; Barhum, Y.; Benhar, M.; Grinberg, L.; Reich, R.; Melamed, E.; Atlas, D. A low molecular weight copper chelator crosses the blood-brain barrier and attenuates experimental autoimmune encephalomyelitis. J. Neurochem. 2004, 89, 1241-1251. [CrossRef] [PubMed]

13. Zhang, H.; Qi, Y.; Yuan, Y.; Cai, L.; Xu, H.; Zhang, L.; Su, B.; Nie, H. Paeoniflorin Ameliorates Experimental Autoimmune Encephalomyelitis via Inhibition of Dendritic Cell Function and Th17 Cell Differentiation. Sci. Rep. 2017, 7, 41887. [CrossRef] [PubMed]

14. Ichiyama, K.; Sekiya, T.; Inoue, N.; Tamiya, T.; Kashiwagi, I.; Kimura, A.; Morita, R.; Muto, G.; Shichita, T.; Takahashi, R.; et al. Transcription factor Smad-independent T helper 17 cell induction by transforming-growth factor- $\beta$ is mediated by suppression of eomesodermin. Immunity 2011, 34, 741-754. [CrossRef] [PubMed]

15. Nicolson, K.; Freland, S.; Weir, C.; Delahunt, B.; Flavell, R.A.; Backstrom, B.T. Induction of experimental autoimmune encephalomyelitis in the absence of c-Jun N-terminal kinase 2. Int. Immunol. 2002, 14, 849-856. [CrossRef] [PubMed]

16. Tran, E.H.; Azuma, Y.T.; Chen, M.; Weston, C.; Davis, R.J.; Flavell, R.A. Inactivation of JNK1 enhances innate IL-10 production and dampens autoimmune inflammation in the brain. Proc. Natl. Acad. Sci. USA 2006, 103, 13451-13456. [CrossRef] [PubMed]

17. Bennett, B.L.; Sasaki, D.T.; Murray, B.W.; O'Leary, E.C.; Sakata, S.T.; Xu, W.; Leisten, J.C.; Motiwala, A.; Pierce, S.; Satoh, Y.; et al. SP600125, an anthrapyrazolone inhibitor of Jun N-terminal kinase. Proc. Natl. Acad. Sci. USA 2001, 98, 13681-13686. [CrossRef] [PubMed]

18. Hoepner, R.; Bagnoud, M.; Pistor, M.; Salmen, A.; Briner, M.; Synn, H.; Schrewe, L.; Guse, K.; Ahmadi, F.; Demir, S.; et al. Vitamin D increases glucocorticoid efficacy via inhibition of mTORC1 in experimental models of multiple sclerosis. Acta Neuropathol. 2019, 138, 443-456. [CrossRef] [PubMed]

19. Hoffman, W.P.; Ness, D.K.; van Lier, R.B. Analysis of rodent growth data in toxicology studies. Toxicol. Sci. 2002, 66, 313-319. [CrossRef] [PubMed]

20. ThermoFischer. Available online: https://www.thermofisher.com/ch/en/home/life-science/pcr/real-timepcr/real-time-pcr-learning-center/real-time-pcr-basics/efficiency-real-time-pcr-qpcr.html (accessed on 21 September 2020).

21. Yamasaki, T.; Kawasaki, H.; Nishina, H. Diverse Roles of JNK and MKK Pathways in the Brain. J. Signal. Transduct. 2012, 2012, 459265. [CrossRef] [PubMed]

22. Raphael, I.; Nalawade, S.; Eagar, T.N.; Forsthuber, T.G. T cell subsets and their signature cytokines in autoimmune and inflammatory diseases. Cytokine 2015, 74, 5-17. [CrossRef] [PubMed]

23. Brehm, M.A.; Daniels, K.A.; Welsh, R.M. Rapid production of TNF-alpha following TCR engagement of naive CD8 T cells. J. Immunol. 2005, 175, 5043-5049. [CrossRef] [PubMed]

24. Schroder, K.; Hertzog, P.J.; Ravasi, T.; Hume, D.A. Interferon-gamma: An overview of signals, mechanisms and functions. J. Leukoc. Biol. 2004, 75, 163-189. [CrossRef] [PubMed]

25. Parameswaran, N.; Patial, S. Tumor necrosis factor- $\alpha$ signaling in macrophages. Crit. Rev. Eukaryot. Gene Expr. 2010, 20, 87-103. [CrossRef]

26. Lau, L.T.; Yu, A.C. Astrocytes produce and release interleukin-1, interleukin-6, tumor necrosis factor alpha and interferon-gamma following traumatic and metabolic injury. J. Neurotrauma 2001, 18, 351-359. [CrossRef] [PubMed]

27. Haider, S.; Pal, R. Integrated analysis of transcriptomic and proteomic data. Curr Genom. 2013, 14, 91-110. [CrossRef] [PubMed]

28. Lassmann, H.; Bradl, M. Multiple sclerosis: Experimental models and reality. Acta Neuropathol. 2017, 133, 223-244. [CrossRef]

29. Zamvil, S.S.; Steinman, L. The T lymphocyte in experimental allergic encephalomyelitis. Annu. Rev. Immunol. 1990, 8, 579-621. [CrossRef] 
30. Sosa, R.A.; Murphey, C.; Robinson, R.R.; Forsthuber, T.G. IFN-gamma ameliorates autoimmune encephalomyelitis by limiting myelin lipid peroxidation. Proc. Natl. Acad. Sci. USA 2015, 112, E5038-E5047. [CrossRef]

31. Arellano, G.; Ottum, P.A.; Reyes, L.I.; Burgos, P.I.; Naves, R. Stage-Specific Role of Interferon-Gamma in Experimental Autoimmune Encephalomyelitis and Multiple Sclerosis. Front. Immunol. 2015, 6, 492. [CrossRef]

32. Naves, R.; Singh, S.P.; Cashman, K.S.; Rowse, A.L.; Axtell, R.C.; Steinman, L.; Mountz, J.D.; Steele, C.; De Sarno, P.; Raman, C. The interdependent, overlapping, and differential roles of type I and II IFNs in the pathogenesis of experimental autoimmune encephalomyelitis. J. Immunol. 2013, 191, 2967-2977. [CrossRef]

33. Baker, D.; Butler, D.; Scallon, B.J.; O’Neill, J.K.; Turk, J.L.; Feldmann, M. Control of established experimental allergic encephalomyelitis by inhibition of tumor necrosis factor (TNF) activity within the central nervous system using monoclonal antibodies and TNF receptor-immunoglobulin fusion proteins. Eur. J. Immunol. 1994, 24, 2040-2048. [CrossRef] [PubMed]

34. Suvannavejh, G.C.; Lee, H.O.; Padilla, J.; Dal Canto, M.C.; Barrett, T.A.; Miller, S.D. Divergent roles for p55 and p75 tumor necrosis factor receptors in the pathogenesis of MOG(35-55)-induced experimental autoimmune encephalomyelitis. Cell Immunol. 2000, 205, 24-33. [CrossRef] [PubMed]

35. Lenercept Multiple Sclerosis Study Group; The University of British Columbia MS/MRI Analysis Group. TNF neutralization in MS: Results of a randomized, placebo-controlled multicenter study. Neurology 1999, 53, 457-465. [CrossRef]

36. Liu, J.; Marino, M.W.; Wong, G.; Grail, D.; Dunn, A.; Bettadapura, J.; Slavin, A.J.; Old, L.; Bernard, C.C. TNF is a potent anti-inflammatory cytokine in autoimmune-mediated demyelination. Nat. Med. 1998, 4, 78-83. [CrossRef] [PubMed]

37. Eugster, H.P.; Frei, K.; Bachmann, R.; Bluethmann, H.; Lassmann, H.; Fontana, A. Severity of symptoms and demyelination in MOG-induced EAE depends on TNFR1. Eur. J. Immunol. 1999, 29, 626-632. [CrossRef]

38. Taoufik, E.; Tseveleki, V.; Chu, S.Y.; Tselios, T.; Karin, M.; Lassmann, H.; Szymkowski, D.E.; Probert, L. Transmembrane tumour necrosis factor is neuroprotective and regulates experimental autoimmune encephalomyelitis via neuronal nuclear factor-kappaB. Brain 2011, 134, 2722-2735. [CrossRef]

39. Palumbo, S.; Pellegrini, S. Experimental In Vivo Models of Multiple Sclerosis: State of the Art. In Multiple Sclerosis: Perspectives in Treatment and Pathogenesis; Zagon, I.S., McLaughlin, P.J., Eds.; Codon Publications: Singapore, 2017.

40. Dong, C.; Yang, D.D.; Wysk, M.; Whitmarsh, A.J.; Davis, R.J.; Flavell, R.A. Defective T cell differentiation in the absence of Jnk1. Science 1998, 282, 2092-2095. [CrossRef]

41. Yang, D.D.; Conze, D.; Whitmarsh, A.J.; Barrett, T.; Davis, R.J.; Rincón, M.; Flavell, R.A. Differentiation of CD4+ T cells to Th1 cells requires MAP kinase JNK2. Immunity 1998, 9, 575-585. [CrossRef]

42. Sabapathy, K.; Kallunki, T.; David, J.P.; Graef, I.; Karin, M.; Wagner, E.F. c-Jun NH2-terminal kinase (JNK)1 and JNK2 have similar and stage-dependent roles in regulating $\mathrm{T}$ cell apoptosis and proliferation. J. Exp. Med. 2001, 193, 317-328. [CrossRef]

43. Weiss, L.; Whitmarsh, A.J.; Yang, D.D.; Rincón, M.; Davis, R.J.; Flavell, R.A. Regulation of c-Jun NH(2)-terminal kinase (Jnk) gene expression during T cell activation. J. Exp. Med. 2000, 191, 139-146. [CrossRef]

44. Sehgal, V.; Ram, P.T. Network Motifs in JNK Signaling. Genes Cancer 2013, 4, 409-413. [CrossRef] [PubMed]

45. Melino, M.; Hii, C.S.; McColl, S.R.; Ferrante, A. The effect of the JNK inhibitor, JIP peptide, on human T lymphocyte proliferation and cytokine production. J. Immunol. 2008, 181, 7300-7306. [CrossRef] [PubMed]

46. Pellegrini, J.D.; De, A.K.; Kodys, K.; Puyana, J.C.; Furse, R.K.; Miller-Graziano, C. Relationships between T lymphocyte apoptosis and anergy following trauma. J. Surg. Res. 2000, 88, 200-206. [CrossRef] [PubMed]

47. DeSilva, D.R.; Feeser, W.S.; Tancula, E.J.; Scherle, P.A. Anergic T cells are defective in both jun NH2-terminal kinase and mitogen-activated protein kinase signaling pathways. J. Exp. Med. 1996, 183, 2017-2023. [CrossRef]

48. Mocholi, E.; Dowling, S.D.; Botbol, Y.; Gruber, R.C.; Ray, A.K.; Vastert, S.; Shafit-Zagardo, B.; Coffer, P.J.; Macian, F. Autophagy is a Tolerance-Avoidance Mechanism that Modulates TCR-Mediated Signaling and Cell Metabolism to Prevent Induction of T Cell Anergy. Cell Rep. 2018, 24, 1136-1150. [CrossRef]

49. Assi, K.; Pillai, R.; Gómez-Muñoz, A.; Owen, D.; Salh, B. The specific JNK inhibitor SP600125 targets tumour necrosis factor-alpha production and epithelial cell apoptosis in acute murine colitis. Immunology 2006, 118, 112-121. [CrossRef] 
50. Himes, S.R.; Sester, D.P.; Ravasi, T.; Cronau, S.L.; Sasmono, T.; Hume, D.A. The JNK are important for development and survival of macrophages. J. Immunol. 2006, 176, 2219-2228. [CrossRef]

51. Zhang, L.; Xie, H.; Cui, L. Activation of astrocytes and expression of inflammatory cytokines in rats with experimental autoimmune encephalomyelitis. Exp. Ther. Med. 2018, 16, 4401-4406. [CrossRef]

52. Liddelow, S.A.; Barres, B.A. Reactive Astrocytes: Production, Function, and Therapeutic Potential. Immunity 2017, 46, 957-967. [CrossRef]

53. Imai, Y.; Ibata, I.; Ito, D.; Ohsawa, K.; Kohsaka, S. A novel gene iba1 in the major histocompatibility complex class III region encoding an EF hand protein expressed in a monocytic lineage. Biochem. Biophys. Res. Commun. 1996, 224, 855-862. [CrossRef]

54. Sloka, S.; Metz, L.M.; Hader, W.; Starreveld, Y.; Yong, V.W. Reduction of microglial activity in a model of multiple sclerosis by dipyridamole. J. Neuroinflamm. 2013, 10, 89. [CrossRef] [PubMed]

55. Waetzig, V.; Czeloth, K.; Hidding, U.; Mielke, K.; Kanzow, M.; Brecht, S.; Goetz, M.; Lucius, R.; Herdegen, T.; Hanisch, U.K. c-Jun N-terminal kinases (JNKs) mediate pro-inflammatory actions of microglia. Glia 2005, 50, 235-246. [CrossRef] [PubMed]

56. Parkinson, D.B.; Bhaskaran, A.; Arthur-Farraj, P.; Noon, L.A.; Woodhoo, A.; Lloyd, A.C.; Feltri, M.L.; Wrabetz, L.; Behrens, A.; Mirsky, R.; et al. c-Jun is a negative regulator of myelination. J. Cell Biol. 2008, 181, 625-637. [CrossRef] [PubMed]

57. Yang, D.D.; Kuan, C.Y.; Whitmarsh, A.J.; Rincón, M.; Zheng, T.S.; Davis, R.J.; Rakic, P.; Flavell, R.A. Absence of excitotoxicity-induced apoptosis in the hippocampus of mice lacking the Jnk3 gene. Nature 1997, 389, 865-870. [CrossRef]

58. Ha, D.; Bing, S.J.; Ahn, G.; Kim, J.; Cho, J.; Kim, A.; Herath, K.H.I.N.M.; Yu, H.S.; Jo, S.A.; Cho, I.-H.; et al. Blocking glutamate carboxypeptidase II inhibits glutamate excitotoxicity and regulates immune responses in experimental autoimmune encephalomyelitis. FEBS J. 2016, 283, 3438-3456. [CrossRef]

59. Pitt, D.; Werner, P.; Raine, C.S. Glutamate excitotoxicity in a model of multiple sclerosis. Nat. Med. 2000, 6, 67-70. [CrossRef]

60. Kuan, C.Y.; Whitmarsh, A.J.; Yang, D.D.; Liao, G.; Schloemer, A.J.; Dong, C.; Bao, J.; Banasiak, K.J.; Haddad, G.G.; Flavell, R.A.; et al. A critical role of neural-specific JNK3 for ischemic apoptosis. Proc. Natl. Acad. Sci. USA 2003, 100, 15184-15189. [CrossRef]

61. Jurewicz, A.; Matysiak, M.; Andrzejak, S.; Selmaj, K. TRAIL-induced death of human adult oligodendrocytes is mediated by JNK pathway. Glia 2006, 53, 158-166. [CrossRef]

62. Jurewicz, A.; Matysiak, M.; Tybor, K.; Selmaj, K. TNF-induced death of adult human oligodendrocytes is mediated by c-jun NH2-terminal kinase-3. Brain 2003, 126, 1358-1370. [CrossRef] 